\title{
Temperature and Rate Dependent Fracture in Glass-Filled Polystyrene
}

\author{
Y. W. MAI* \\ Department of Mechanical Engineering \\ University of Michigan \\ Ann Arbor, Michigan
}

\begin{abstract}
The rate and temperature dependent fracture behavior of glass-filled polystyrene has been investigated over the crack speed range of $10^{-3}$ to $1 \mathrm{~mm} / \mathrm{sec}$ and in the temperature range 283 to $396^{\circ} \mathrm{K}$ for three environmental conditions: (i) air; (ii) water; and (iii) hot water exposure at $363^{\circ} \mathrm{K}$ and subsequent drying. Relationships between fracture toughness $\left(K_{c}\right)$, crack speed and temperature have been obtained experimentally and analysed according to the concepts of fracture mechanics and reaction rate theories. Crack propagation in air is shown to be controlled by a $\beta$-relaxation process associated with crazing. Activation energies of $200 \sim 210 \mathrm{~kJ} /$ mole in air and $80 \sim 120$ $\mathrm{kJ} /$ mole in water are reported. At a given temperature and crack speed, the glass-filled polystyrene is shown to display smaller crack propagation resistances in a water environment when compared with the air results. Specimens subjected to hot water exposure and then tested after drying also possess less cracking resistance. This toughness degradation phenomenon is a result of the damaging effects of the water which penetrates into the glass-filled composite.
\end{abstract}

\section{INTRODUCTION}

$\mathrm{D}$ espite considerable analytical and experimental research devoted to determine composite tensile strengths and composite moduli of polymers reinforced with randomly oriented short glass fibers (1-6), fewer investigations have been directed towards the measurement of fracture toughness $\left(K_{c}\right)$, which uniquely defines the resistance to crack propagation. Previous studies have shown that, for viscoelastic polymers, the fracture toughness is dependent on crack speed $(\boldsymbol{a})$, temperature $(T)$ and absorption of liquid environments (7-15). Relationships between these variables (i.e., $K_{c}$, $a, T)$ for polymeric materials such as polymethylmethacrylate, ABS and polystyrene, have been developed using the concepts of elastic fracture mechanics (7-15) and also the chemical rate theory analyses $(13,14,16)$. Successful applications of fracture mechanics to interpret fracture properties of short-fiber reinforced composites (e.g., glass-filled polyphenylene oxide and acetal copolymer) have also been reported by Wambach et al. (17), Hardy (18), and Broutman and Sahu (19). In all these previous studies, the primary interest, however, was centered on the effects of filler content and glass/ matrix adhesion on the composite fracture toughness. No attention was then given to the functional dependence of fracture toughness on crack speed, temperature, and test environment.

* Present address: Polymer Lngincering Group, Departntent of Mechanical Engineering, Imperial College of Science and Techuology, Exhibition Road, London SW7 2BX, Englamed
The present investigation examines the use of fracture mechanics and reaction rate equations in describing the rate-temperature dependent fracture of a typical polymer, polystyrene, reinforced with randomly oriented short glass fibers. In the experimental studies, we have chosen water as the testing environment because its adverse effects on the strengths of the glass fibers as well as the glass/matrix interface are well known $(20,21)$. Single edge notched (SEN) tensile specimens are used to derive the $K_{c}(i)$ relationships for the glassfilled polystyrene for a temperature range of 283 to $363^{\circ} \mathrm{K}$ and for three environmental conditions: (i) air, (ii) water, and (iii) air, but previously soaked in hot water at $363^{\circ} \mathrm{K}$ for $12 \mathrm{hrs}$ and oven-dried. These experimental results are then analyzed according to the Williams/ Marshall relaxation controlled crack growth model (7) and also the $K_{c}$-biased rate equation (16).

\section{EXPERIMENTAL}

\section{Materials and Specimen Geometry}

Ready-mixed glass reinforced polystyrene pellets* (glass 20 percent by weight) were supplied through the courtesy of Thermofil Company (Michigan). Standard dumb-bell shape tensile specimens with dimensions shown in Fig. $I$ were injection molded in our own labo-

* The polystrene was a general purpose grade product of Monsanto Company (CSA) and $6 \mathrm{~mm}$ chopped F-ylass fibers were nsed as the reinforcing medium. This fiberglass has at tensile strength of abont $1.38 \mathrm{GN} / \mathrm{m}^{2}$ with a diuneter of $10 \mu \mathrm{m}$ and an aspect ration of 625 . 
ratory and then converted into single edge notch (SEN) fracture toughness tensile specimens. Starter cracks were introduced in the specimens by sawing to approximately the required depth and then notching with a razor blade. All starter cracks were approximately $3 \mathrm{~mm}$

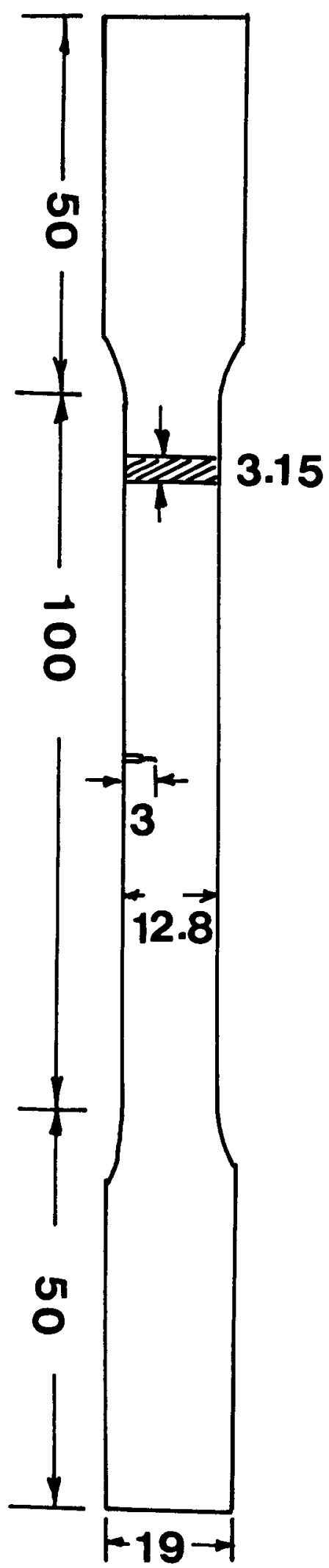

Fig. 1. A single edge notched fracture toughness specimen. All dimensions in $\mathrm{mm}$. long. Because of the lack of suitable equipment on the injection molder, we have not been able to make more satisfactory toughness specimens such as the double cantilever beam geometry.

In total, three series of cracking experiments were performed using these SEN specimens. In the first two series, fracture tests were conducted in air and water respectively, with temperature and crosshead rate varying between selected limits. It is expected that this will yield $K_{c}(i, T)$ relationships for the glass-filled composite in these two environments, thus enabling a comparison of their results. As pointed out by Ishai (21), the effects of water penetration into glass fiber reinforced plastics may be residual or reversible. To study the residual effect, if any, on the fracture properties of the composite, a third series of experiments was performed. Thus, SEN specimens were first heated in water at $363^{\circ} \mathrm{K}$ for about $12 \mathrm{hrs}$, and then dried in an oven at $343^{\circ} \mathrm{K}$ for two hrs and left to normalize at room temperature before the fracture tests.

\section{Test Methods and Derivations}

All experiments were performed in an Instron testing machine with crosshead speeds varying between 8.33 $\mu \mathrm{m} / \mathrm{sec}$ and $1 \mathrm{~mm} / \mathrm{sec}$. Except for low crosshead rates, load/time traces for rates greater than $100 \mu \mathrm{m} / \mathrm{sec}$ were recorded in an oscilloscope. An environmental chamber fitted for use with the Instron was utilized for the temperature and environmental experiments. Temperatures were varied between 283 and $363^{\circ} \mathrm{K}$, the actual temperatures being measured with a copper-constantan thermocouple adhered to the specimen surface during the tests. For the environmental fracture experiments, plastic reservoirs were constructed onto the SEN specimens so that when filled with water, the crack was totally submerged.

By recording the starter crack length $(a)$ and the fracture load $(P)$ at the instant of crack initiation, it is possible to calculate the corresponding fracture toughness $\left(K_{c}\right)$ given by:

$$
K_{c}=\frac{P}{B W} \sqrt{a} Y
$$

where $B, W$ are thickness and width of specimen, and $Y$ is the finite width correction factor and is a function of $a / W(22)$. Because the SEN specimen has a bad geometrical stability factor $(23,24)$ and hence exhibits little slow crack growth before instability, it is difficult to measure experimentally the crack velocity in the early stages of growth. Instead, crack velocities are estimated from a modified 'apparent' crack speed expression determined from either a crack tip stress rate or strain rate analysis $(25,26)$ which gives:

$$
a=\frac{1}{\sqrt{2} \pi t}\left(\frac{K_{c}}{\sigma_{d}}\right)^{2}
$$

where $t$ is the time to fracture initiation in the cracking experiment and $\sigma_{d}$ is the debonding strength, which replaces the yield strength $\left(\sigma_{y}\right)$ in the original derivations $(25,26)$. Good agreement between the calculated $a$ and the actual measured crack speeds has been re- 
ported by Williams et al. (27) and Marshallet al. (15) for crack propagation in PMMA and polystyrene. Because of the planar isotropy of the present material, we have also adopted $E q 2$ to calculate $\boldsymbol{i}$ and thus generated many $\left(K_{c}, \boldsymbol{a}\right)$ data. The reason for using $\sigma_{d}$ instead of $\sigma_{y}$ is given in the next section.

\section{RESULTS AND DISCUSSION}

\section{Validity of Fracture Mechanics Approach}

At one time the main concern in the present investigation was whether the SEN geometry converted from dumb-bell tensile bars could be a valid fracture toughness specimen. To check this, we have preformed notches of various depths ranging from $a / W=0.10$ to 0.40 onto the narrow edges of the tensile specimens and then fractured them in the Instron testing machine at a constant crosshead rate. The 'corrected' fracture stresses $\left(\sigma_{f} Y\right)$ were then plotted against $a^{-\frac{1}{2}}$, where a line could be drawn passing through approximately all the experimental data. The slope of this line gives the $K_{c}$ value of the glass-filled polystyrene at the given test conditions. If fracture mechanics analysis cannot be used for this testpiece geometry, these data should not have been rationalized in the $\sigma_{f} Y$ vs $a^{-\frac{1}{2}}$ plots. In addition, a check on the size requirements for a valid plane strain fracture toughness test (22), such as the damage (analogous to plastic) zone size relative to the starter crack length etc., show that all these conditions are met but the thickness requirement. In view of this, the results reported here are all designated as $K_{c}$ and not $K_{I c}$, although it is plausible that the stress state at the crack tip is close to the plane strain condition because of the additional constraint in the transverse direction provided by the glass fibers. It was further noted that in all these fracture experiments, the fracture stresses $\left(\sigma_{f}\right)$ were always less than $0.7 \sigma_{t}\left(\sigma_{t}\right.$ being the tensile strength). We therefore believed that the present SEN specimens were valid for fracture toughness evaluation, and that the $K_{c}$ values thus obtained were genuine. It should be noted in passing that Hardy (18) has also successfully used SEN testpieces converted from much smaller dumb-bell tensile bars to measure $K_{I C}$ values of glass-filled acetal copolymers. Much later in our investigation, we found that the SEN testpieces when sectioned down to a uniform depth could be usefully tested in three-point bending. This test configuration gave much better stability of cracking $(23,24)$ and thus provided some measurable slow crack growth.

As observed in this investigation and pointed out by Gaggar and Broutman (28), randomly oriented glass fiber-resin composites do not yield but debond between the matrix and fiber. It was thought that since this crack tip debonding process was analogous to the plastic (or craze) zone growth process in metals (and polymers), all the pertinent LEFM equations could be modified for use in describing fracture properties of glass-filled polymers. However, the debonding strength in composites must be used instead of the yield strength in metals and polymers. Gaggar and Broutman (28) have provided some evidence of this concept by obtaining good agree- ment between the measured debonded zone sizes and calculated results based on modified debonded zone size expressions for a glass fiber reinforced polyester resin. In a similar way, $E q 2$ is used to calculate the apparent crack speed (which therefore measures the debonded zone growth rate). The debonding stress $\left(\sigma_{d}\right)$ at each temperature and strain rate was determined independently with uniaxial unnotched tensile specimens, and (for calculation purposes) was taken as the 0.2 percent offset value on the stress-strain curves. The Young's modulus $(E)$ measured from the slope of the linear part of the stress-strain curve varies with temperature and strain rate $(\dot{\epsilon})$ according to the relation, where $E=12.5$ $\dot{\epsilon}^{0.05}-0.0162 T\left(\mathrm{GN} / \mathrm{m}^{2}\right)$. The uniaxial strain $\left(\epsilon_{d}\right)$ corresponding to $\sigma_{d}$ is roughly $0.012 \sim 0.014$ for all temperatures investigated. Although we have not measured the crack speeds and compared them with the calculated $a$ for the SEN specimens under uniaxial tension, we have, however, performed some preliminary experiments using the SEN testpieces in three-point bending, where at slow crosshead speeds the measured crack speeds compared reasonably well with those calculated from $E q$ 2. These limited amount of three-point bending $\left(K_{c}, a\right)$ results also fit fairly well with the SEN data given in Fig. 2. Thus, Eq 2 may be reasonably used as a means of calculating $a$. Until further experiments using much better fracture toughness specimen geometries which ensure the measurements of both $K_{c}$ and $a$ are performed, we cannot make a more critical comparison with our crack velocity data presented in this paper.

\section{Fracture Toughness and Crack Velocity Relationships}

The fracture toughness-crack velocity relationships for the glass-filled polystyrene for temperatures of 296 to $363^{\circ} \mathrm{K}$ and for the crack speed range of $10^{-3}$ to $10 \mathrm{~mm} / \mathrm{sec}$ are shown in Figs. 2 and 3. In Fig. 2, the open symbols refer to those experiments performed in an air environment and the solid symbols to those experiments in which the specimens were exposed in hot water at $363^{\circ} \mathrm{K}$ for 12 hrs, oven-dried and then tested in air. Figure 3

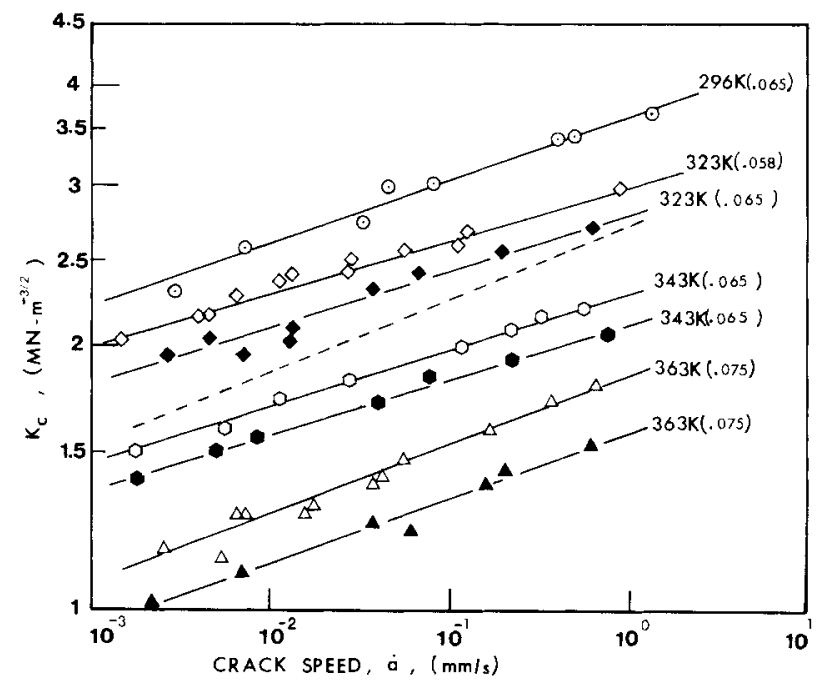

Fig. 2. Variations of fracture toughness $\left(K_{r}\right)$ with crack speed $(a)$ for the glass-filled polystyrene. Open symbols for tests in air and solid symbols for tests in which specimens have been exposed to hot water absorption and subsequent drying. 


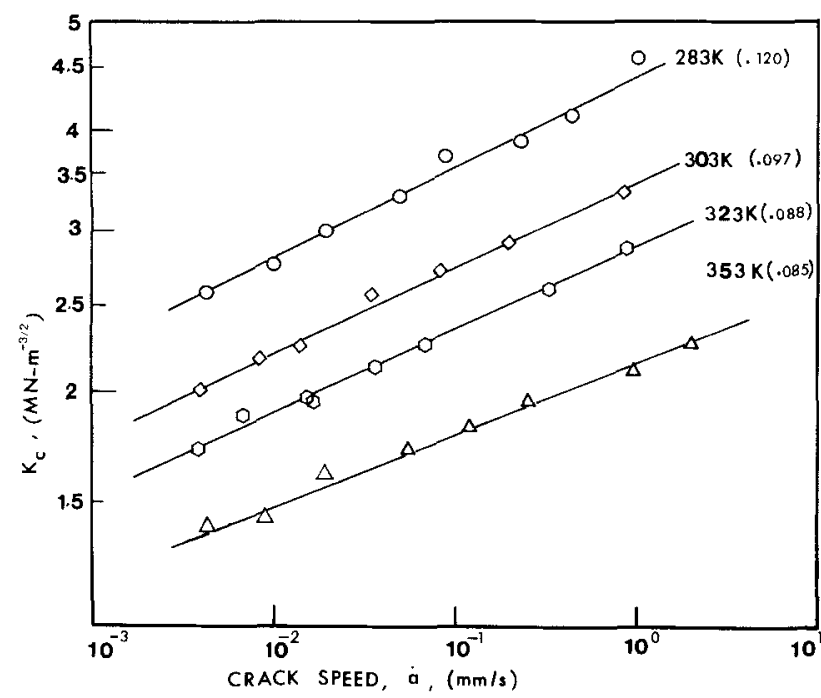

Fig. 3. Fracture toughness $\left(K_{\text {. }}\right)$ and crack velocity $(\boldsymbol{a})$ relations at various temperatures. Tests conducted in water.

presents the $K_{c}(i, T)$ data obtained in a water environment. In general, it may be seen that at a given temperature and environmental condition, the crack speeds increase with increasing $K_{c}$ values, and decrease with temperature at a given magnitude of $K_{\varepsilon}$. The straight line relationships observed in Figs. 2 and 3 suggest that all the $\left(K_{c}, a\right)$ data at a given temperature and test condition may be represented by the following equation:

$$
K_{c}=A \dot{a}^{p}
$$

where $A$ and $p$ are constants depending on temperature and test environment. The individual values of $p$ are given in parentheses in the figures. It appears that for a given environmental condition $p$ is more or less constant for the temperatures involved. Individual values of $A$ and $p$ are given in Table 1 .

It should be noted that in crack speed estimations using $E q 2, \sigma_{d}$ is a function of temperature and test environment. Such functional relations have been determined independently and used in our $\dot{a}$ calculations.

Williams and Marshall (7) have recently presented an analysis for predictions in $K_{c}(a)$ relations for environmental crack and craze growth in polymeric materials. Based on a crack opening displacement $(\delta)$ fracture criterion $(7,26)$ and incorporating into the analysis the time dependent elastic properties of the material, they give:

Table 1. Values of $A$ and $p$ in Equation $3^{\star}$ for Different Environmental Conditions

\begin{tabular}{lcrc}
\hline Environmental condition & Temperature, ${ }^{\circ} \mathbf{K}$ & $\mathbf{A}$ & $\mathbf{p}$ \\
\hline \multirow{3}{*}{ Water } & 283 & 10.84 & 0.120 \\
& 303 & 6.83 & 0.097 \\
& 323 & 5.34 & 0.088 \\
Air & 353 & 3.95 & 0.085 \\
& 296 & 5.54 & 0.065 \\
& 323 & 4.49 & 0.058 \\
Hot water absorption & 343 & 3.62 & 0.065 \\
and subsequent drying & 363 & 3.12 & 0.075 \\
& 323 & 4.26 & 0.065 \\
& 343 & 3.34 & 0.065 \\
& 363 & 2.67 & 0.075 \\
\hline
\end{tabular}

" $K$ in $\mathrm{MN} / \mathrm{m}^{3}$ and $\dot{a}$ in $\mathrm{m} / \mathrm{sec}$.

$$
K_{c}=C a^{\frac{m+n}{2(1-m+n)}}
$$

for relaxation controlled crack growth processes. $m$ and $n$ are measures of the time dependent response of the yield stress $\left(\sigma_{y}\right)$ and Young's modulus $(E)$, respectively, and $C$ is a constant. Williams and Marshall (7) have also shown that for many plain polymeric materials $m$ and $n$ are approximately 0.10 , so that theoretical slopes should be about 0.10 . To apply $E q 4$ to analyze the glass-filled polystyrene data, we have to measure $m$ and $n$ independently, where $n$ now becomes the time dependent response of the debonding stress $\left(\sigma_{d}\right)$. Since we have not measured these values in the present study, we cannot compare the theoretical slopes (i.e., $m+n / 2(1-m+$ $n$ ) ) with the ones measured (i.e., $p$ in Table 1) in the log $K_{c}$ vs $\log a$ plots. However, it appears that specimens preheated in hot water and then tested dry have not introduced any significant changes in the slopes. But, $p$ values in water are obviously greater than those in air. This therefore indicates possible effects of waterinduced damage or plasticization of the crack tip material.

The crack opening displacement values for crack propagation may be estimated from the following expression, where:

$$
\delta=\frac{K_{c}^{2}}{E \sigma_{d}}
$$

However, both $E$ and $\sigma_{d}$ are crack tip quantities and depend on effective crack tip speed, temperature and test environment. By running standard tensile tests at different strain rates $(\dot{\boldsymbol{\epsilon}})$ and temperatures, both $E(\dot{\boldsymbol{\epsilon}}, T)$ and $\sigma_{d}(\dot{\epsilon}, T)$ relations have been obtained for the glassfilled polystyrene for the three testing conditions. The effective crack tip strain rate is related to the crack speed (a) by $(26,27)$ :

$$
\dot{\boldsymbol{\epsilon}} \simeq \pi \epsilon_{d}^{3}\left(\boldsymbol{E} / K_{c}\right)^{2} \dot{a}
$$

where $\epsilon_{d}$ is the strain of the glass-filled composite corresponding to $\sigma_{d}$ and has a magnitude of approximately $0.012 \sim 0.014$. Thus, given $\left(K_{c}, \dot{a}\right), \dot{\boldsymbol{\epsilon}}$ can be solved numerically from $E q 6$, and from this value of $\dot{\epsilon}$, corresponding $E$ and $\sigma_{d}$ values can be estimated from previously established data and used in $E q 5$ to give $\delta$. For example, we have found that for temperatures between 296 and $363^{\circ} \mathrm{K}, \delta$ varies from $12 \mu \mathrm{m}$ to $20 \mu \mathrm{m}$ when tested in air. However, $\delta$ values tested in water at the same temperature range are smaller, e.g., at $323^{\circ} \mathrm{K}, \delta$ is approximately $12 \mu \mathrm{m}$ in water as opposed to $16 \mu \mathrm{m}$ in air.

Other than the Williams/Marshall relaxation controlled crack growth model which has been shown in the above analysis to apply well to the $K_{r}(\boldsymbol{a}, T)$ experimental data for the glass-filled polystyrene, chemical rate theory analyses can also be applied which, in addition to giving elegant $K_{c}(i, T)$ relationships, also provide activation energies for the particular molecular relaxation process involved. Atkins $e t$ al. (13) have successfully shown that a $R$-biased Ree-Eyring activation equation*

${ }^{*} R=K_{r} / E$ for cerasi-static cracking, and is a symbol used in Gurney and Maj (23) to represent fracture work per unit crack area. 
can be applied to analyze the $R(a, T)$ data for PMMA. An alternative $K_{c}$-biased equation has also been used by Weiderhorn (16) to describe the slow crack growth in glass and ceramics. Thus:

$$
a=D \exp \left(\frac{-U+F K_{c}}{k T}\right)
$$

where $D$ and $F$ are constants, $k$ the Boltzman constant and $U$ the activation energy.

The original data shown in Figs. 2 and 3 have been re-drawn in Figs. 4 and 5 in which $\log a$ is plotted against $K_{c} / T$. These results show that the $K_{c}$-biased activation equation given in $E q 7$ can also be used adequately to describe the rate-temperature dependent fracture in glass-filled polystyrene. The activation energies calculated from the results shown in Fig. 4 are $200 \sim 210$ $\mathrm{kJ} / \mathrm{mole}$ for the two series of experiments done in air for $T$ between 296 and $363^{\circ} \mathrm{K}$. These values are in close agreement with those reported for a $\beta$-relaxation process in polystyrene (29) associated with crazing. It is thus apparent that fracture initiation in the glass-filled composite under consideration is controlled by a molecular process involving crazing of the matrix material. The glass fibers provide the reinforcements to the composite during crack propagation only. The activation energy for the fracture process in water can be deduced from Fig. 5 . However, since the slopes for these $K_{c}(\dot{a})$ lines at different temperatures do not have the same magnitude, different $U$ values may be calculated depending on the particular slope and crack speed chosen. For example, the activation energies obtained are 80,95 and 120 $\mathrm{kJ} / \mathrm{mole}$ for $\boldsymbol{a}$ equal to $10^{-2}, 10^{-1}$ and $1 \mathrm{~mm} / \mathrm{sec}$ respectively when $F / k=1.42 \times 10^{3} \mathrm{MN}^{-1}-\mathrm{m}^{3 / 2}-{ }^{\circ} \mathrm{K}$ (i.e.,

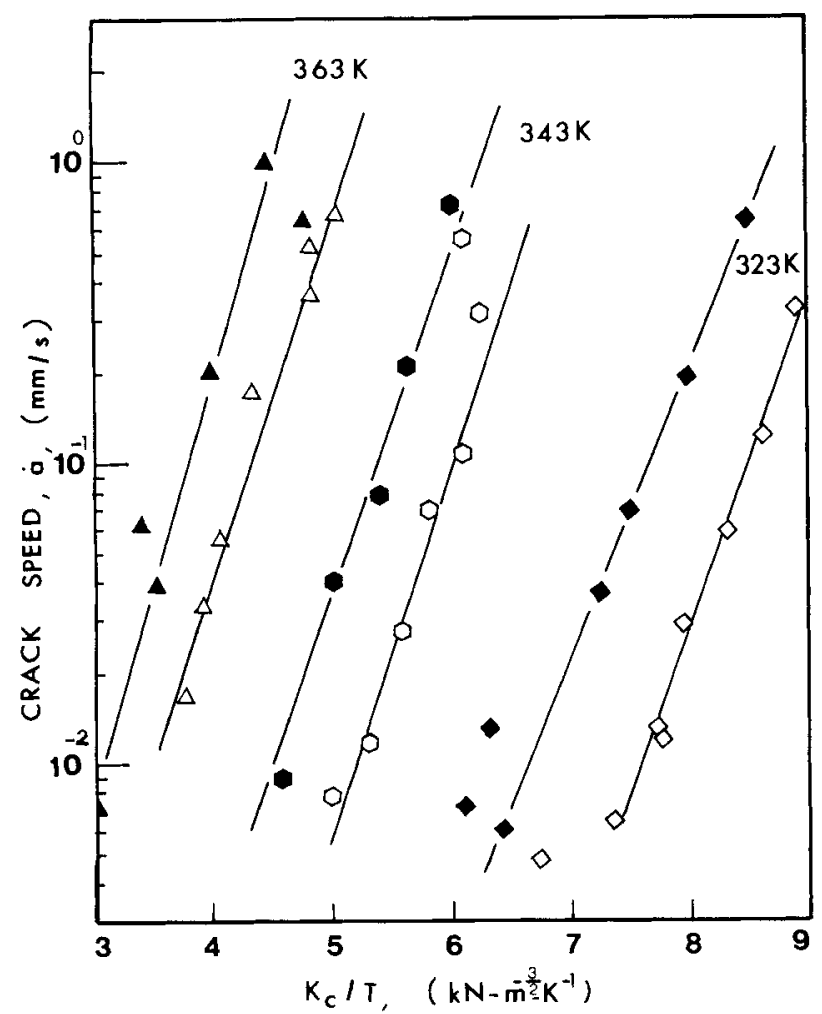

Fig. 4. A plot of crack speed against $K_{r} / T$. Solid symbols for specimens with hot water absorption and subsequent drying. Open symbols for tests in air.

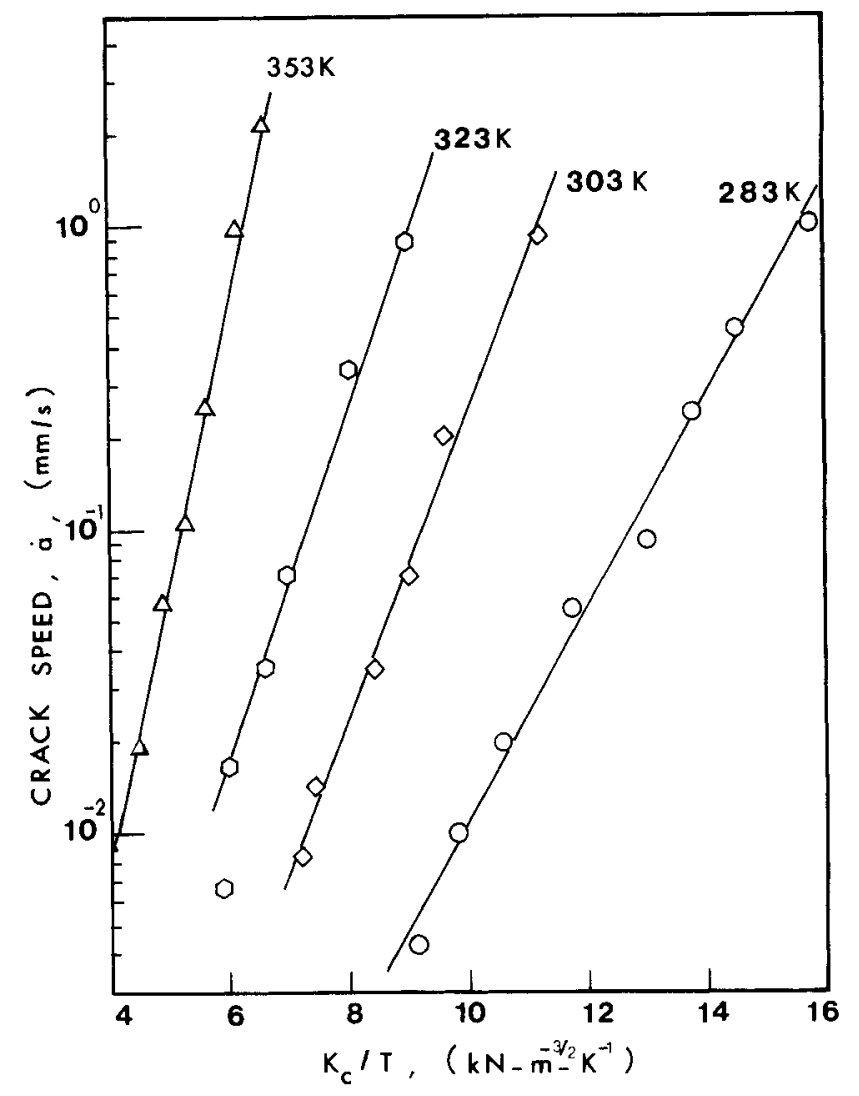

Fig. 5. A plot of crack speed against $K_{c} / T$ for tests in water at various temperatures.

slope for $323^{\circ} \mathrm{K}$ line) is chosen. These results suggest that in the presence of water, the activation energy has been reduced considerably. Note that pre-exposure in hot water (and then tested after drying) does not change the activation energy for the fracture process involved.

We have therefore successfully shown that both fracture mechanics and chemical reaction rate theories are adequate in describing the $K_{c}(i, T)$ data for glass-filled polystyrene in air and in a water environment. These theories could be usefully extended to analyze the ratetemperature dependent fracture of other glass-filled polymers. Finally, Williams (30) has suggested that the relaxation controlled crack growth theory in fact also considers the activation energy required for the particular fracture process involved which arises from modulus changes. While this is certainly true, the $K_{c}(i, T)$ relations would then become far more complex and lack the simplicity of $E q 7$. In addition, $n$ has to be determined independently in order that $U$ can be found.

\section{Effects of Water Penetration on Composite Toughness}

Ishai (21) has suggested that there are two effects of water penetration on composite strength. One effect results in the reduction of interfacial toughness and consequently tensile strength in the presence of water, and the other causes stress-environment induced damages such as matrix cracking, interfacial debonding and chemical deterioration of the glass fibers. Obviously, the first effect is reversible but the second is residual because of permanent weakening of the composite internal structure $(31,32)$. Thus, for a given temperature, one 
may expect that the degradation in tensile strength or fracture toughness would be greater in water because the two effects mentioned are additive. When water is driven out by heating, the damage is only that due to any irreversible weakening of the composite. Although the $K_{c}$ values are also reduced in this case, such reductions should not be as intense as in the presence of water.

At this point, it is significant to point out that when fracture toughness comparisons are made for viscoelastic materials, they should be compared on a common crack speed basis. Otherwise, such comparisons may lead to less meaningful if not erroneous conclusions. In Fig. 2, we can clearly see that for given combinations of temperature and crack speed, the fracture toughness $\left(\boldsymbol{K}_{\boldsymbol{c}}\right)$ values are always lower for the specimens subjected to hot water absorption and subsequent drying. A few calculations show that the mean $K_{c}$ reductions for the range of crack velocities given are approximately 6,7 and 15 percent for temperatures of 323,343 and $363^{\circ} \mathrm{K}$, respectively. Such toughness degradations are shown to be a result of matrix weakening and glass/matrix debonding caused by exposure to hot water. This observation agrees well with ideas put forward by Ishai (21).

By comparing the $K_{c}(\dot{a}, T)$ results shown in Figs. 2 and 3 , we can also find corresponding toughness degradations in the presence of water at comparable crack speeds and temperatures. For example, consider the $K_{c}(\boldsymbol{d})$ results at $323^{\circ} \mathrm{K}$ for the three environmental conditions. For convenience, the $K_{c}(i)$ data in water at $323^{\circ} \mathrm{K}$ have been superimposed in Fig. 2 and represented by the dotted line. Thus, it is clearly demonstrated that the physical presence of water has produced the most significant reduction (compared with the solid lines for air and for hot water absorption with subsequent drying) in $K_{r}$ values, particularly at the lower end of the crack speed range. This phenomenon is obviously a result of the combined action of the reversible and residual damage effects caused by water penetration into the glassfilled composites. Note that specimens exposed to hot water absorption at $363^{\circ} \mathrm{K}$ for $12 \mathrm{hrs}$ and subsequent drving show less $K_{c}$ degradations at comparable crack speeds. All these experimental findings thus reinforce ideas discussed in earlier parts of this section.

\section{CONCLUSIONS}

The rate-temperature dependent fracture behavior of glass-filled polystyrene for a temperature range of 283 to $363^{\circ} \mathrm{K}$ and over the crack speed range of $10^{-6}$ to $10^{-2}$ $\mathrm{m} / \mathrm{sec}$ has been investigated for three environmental conditions as given in the earlier parts of this paper. Using SEN specimens, the $K_{c}(i, T)$ data obtained have been shown to follow $K_{c}(i, T)$ relationships given by linear elastic fracture mechanics (e.g., Eq 4 ) and by the toughness-biased Ree-Eyring rate theory (i.e., Eq 7). Crack propagation in air is shown to be relaxation con- trolled and governed by a $\beta$-molecular process associated with crazing of the matrix material.

For a given temperature and crack speed, the glassfilled composite possesses smaller resistances to crack propagation when tested in water and when subjected to hot water absorption and subsequent drying. The fracture toughness degradations observed in water are results of the combined actions of both reversible and residual damage effects due to water penetration into the glass-filled composite.

\section{ACKNOWLEDGMENTS}

The author wishes to thank Thermofil Company (Michigan, USA) for supplying the glass-filled polystyrene pellets used in this investigation and Professor J. G. Williams for useful suggestions and comments on this paper.

\section{REFERENCES}

1. L. H. Lee, Polym. Eng. Sci., 9, 213 (1969).

2. R. E. Lavengood, Polym. Eng. Sci., 12, 48 (1972).

3. J. K. Lees, Polym. Eng. Sci., 8, 186 (1968).

4. Idem, Polym. Eng. Sci., 8, 195 (1968).

5. P. E. Chen, Polym. Eng. Sci, 11, 51 (1971).

6. L. E. Nielsen, J. Appl. Polym. Sci., 10, 97 (1966).

7. J. G. Williams and G. P. Marshall, Proc. Royal Soc. (London), A342, 55 (1975).

8. I. D. Graham et al., "Proc. Dynamic Crack Propagation Conf.," Lehigh University, USA (1972).

9. G. P. Marshall, L. H. Coutts, and J. G. Williams, J. Mater. Sci., 9, 1409 (1974).

10. Y. W. Mai, J. Mater. Sci., 11, 303 (1976).

11. E. H. Andrews, G. M. Levy, and J. Willis, J. Mater. Sci., 8, 1000 (1973).

12. Y. W. Mai, J. Mater, Sci., 10, 943 (1975).

13. A. G. Atkins, C. S. Lee, and R. M. Caddell, J. Mater. Sci., 10, 1381 (1975).

14. F. A. Johnson and J. C. Radon, Eng. Fract. Mech., 4, 555 (1972).

15. G. P. Marshall, L. E. Culver and J. G. Williams, Int.J. Fract., 9, 295 (1973)

16. S. M. Wiederhorn, J. Amer. Ceram. Soc., 50, 407 (1967).

17. A. Wambach, K. Trachte, and A. Dibenedetto, J. Comp. Mater., 2, 266 (1968).

18. G. F. Hardy, J. Appl. Polym. Sci., 15, 853 (1971).

19. L. J. Broutman and S. Sahu, Mater. Sci. Eng., 8, 98 (1971).

20. C. Gurney, Proc. Royal Soc. (London), A242, 24 (1964).

21. Ori Ishai, Polym. Eng. Sci., 15, 491 (1975).

22. W. F. Brown and J. E. Srawley, ASTM STP 410, Philadelphia, USA (1967).

23. C. Gurney and Y. W. Mai, Eng. Fract. Mech., 4, 853 (1972).

24. D. P. Clausing, Int. J. Fract. Mech., 5, 211 (1969).

25. G. R. Irwin, Appl. Mater. Res., 3, 65 (1964).

26. J. G. Williams, Int. J. Fract. Mech., 8, 393 (1972).

27. J. G. Williams, J. C. Radon, and C. E. Tumer, Polym. Eng. Sci., 8, 130 (1968).

28. S. Gaggar and L. J. Broutman, Int. J. Fract., 10, 606 (1974).

29. T. E. Brady and G. S. Y. Yeh, J. Macromol. Sci. Phys., B9, 659 (1974).

30. J. G. Williams, private communication (1976)

31. P. W. R. Beaumont and B. Harris, J. Mater. Sci., 7, 1265 (1972).

32. B. Harris, P. W. R. Beaumont, and E. Moncunill de Ferran, J. Mater. Sci., 6, 238 (1971). 